\title{
Surrogacy in natural patterns of benthic distribution and diversity: selected taxa versus lower taxonomic resolution
}

\author{
Maria Włodarska-Kowalczuk*, Monika Kędra
}

Institute of Oceanology PAS, Powstańców Warszawy 55, 81-712 Sopot, Poland

\begin{abstract}
Surrogates are measures that reflect species-level community patterns, but can be more easily determined. The 2 main surrogacy methods (lowering the resolution of taxonomic identifications and selection of surrogate taxonomic groups) were first developed and widely tested in pollution impact studies. The performance of surrogates in natural benthic variability studies remains largely unexplored. The aim of the present study was to test both surrogacy methods (taxonomic sufficiency and selected taxa) in predicting benthic response (both diversity and distributional patterns) to a natural disturbance gradient produced by glacial sedimentation in an Arctic fjord. There was a strong correlation between benthic diversity and distribution patterns observed at the level of species, genus, and family. Little information was lost when the organisms were identified to the order level only. Additionally, polychaetes extracted from the basic dataset and analyzed separately were good predictors of variability throughout the macrobenthic community. The species distribution and diversity patterns observed along the glacial disturbance gradient did not persist when taxonomic resolution was lowered to the class or phylum level or when only molluscs or crustaceans were analyzed. Comparison of the current results to a number of other marine benthic studies shows that the taxonomic sufficiency of families is very high and consistent across different communities, habitats, and stress-generating factors; thus, families can be recommended as a reliable measure of benthic response to environmental gradients when species identifications are not available.
\end{abstract}

KEY WORDS: Surrogate - Taxonomic sufficiency $\cdot$ Natural variability $\cdot$ Diversity $\cdot$ Soft bottom · Macrofauna $\cdot$ Glacial sedimentation

\section{INTRODUCTION}

Soft bottom benthic communities are probably the most widely used indicators of both natural and anthropogenic environmental changes as they are composed of relatively immobile organisms and their quantitative sampling is quite easy (Warwick 1993). The most commonly used responsive variables include species composition and distribution, explored with multivariate tools and univariate measures of diversity (Clarke \& Warwick 1994). Traditionally, the analysis of both distribution and diversity patterns required a data matrix containing species abundances in samples. However, the identification of all sampled animals to the species level is very expensive as it is time consuming, labor intensive, and requires a considerable level of taxonomic expertise. Pollution monitoring and rapid assessment projects require easier and cheaper methods; this has fueled the search for surrogates in benthic investigations. Surrogates are defined as quantities that reflect species-level community patterns, but can be more easily determined (Olsgard \& Somerfield 2000). Basically, surrogate analysis requires less taxonomic expertise and is less time-consuming and thus less expensive than the species-level identification of all animals found in sampled material. Two different approaches were used in the quest for a perfect surrogate in marine benthic impact studies: (1) lowering the 
taxonomic resolution of the identification of animals and (2) selecting a surrogate taxonomic group that is an indicator of the entire community's variability.

Ellis (1985) introduced the term 'taxonomic sufficiency' for the lowest level of taxonomic resolution required to detect pollution-related changes in benthic communities. The effects of pollution were evident in the higher taxon distribution in the benthic communities of soft bottoms (Warwick 1988a,b, Ferraro \& Cole 1990, Somerfield \& Clarke 1995, Vanderklift et al. 1996) as well as kelp-associated fauna (Smith \& Simpson 1993). Gaston (2000) claimed that the numbers of higher taxa may be a good predictor of species numbers and, as such, are a valid measure of biodiversity. Olsgard et al. (2003), Thompson et al. (2003), and Ferraro \& Cole (1990) tested the applicability of Gaston's hypothesis to marine pollution impact studies, employing benthic diversity as a responsive variable. Other benthic researchers postulated treating the patterns observed for a selected taxonomic group as a proxy of patterns of the whole benthic community (Olsgard \& Somerfield 2000, Olsgard et al. 2003).

Most surrogacy studies conducted in the marine realm have been performed along minimal environmental gradients, with anthropogenic disturbance being the major extrinsic factor affecting the biota. Warwick (1988a) suggested that higher taxonomic group analyses can better describe the effects of anthropogenic pollution than natural patterns of benthic distribution. He stated that natural variables can drive the replacement of closely related species rather than changes in higher taxa composition. Vanderklift et al. (1996) stated that benthic patterns observed along natural gradients may be less robust than those produced by pollution or other anthropogenic disturbances. The taxonomic sufficiency of groups higher than species, however, was documented for benthic communities distributed along natural estuarine gradients (De Biasi et al. 2003, Dethier \& Schoch 2006). Vanderklift et al. (1998) showed that higher taxon diversity can be a useful tool in the conservation management of natural coastal benthic systems. Higher taxon richness mirrored patterns of species diversity in natural benthic communities of deep-sea chemosynthetic systems (Doerries \& Van Dover 2003) or large-scale gradients of eastern Pacific shallow-water molluscs (Roy et al. 1996). Selected taxa may also perform well in investigations of natural patterns (e.g. the number of mollusc species is a good predictor of the invertebrate diversity on Australian rocky shores; Smith 2005).

Most surrogacy publications to date have focused either only on taxonomic sufficiency or only on selected taxa performance. The current study differs in that it tests and compares the performance of both surrogacy methods, and the applicability of the 2 approaches for the study of both diversity and distributional patterns is compared. A similar comparative study was undertaken by Olsgard et al. (2003), but their study was limited only to polychaetes and did not encompass the whole macrobenthic community. Moreover, the majority of the surrogacy tests were performed on data from severe anthropogenic disturbance impact studies. There are still only a few publications on the effectiveness of surrogate-based analyses in the detection of natural patterns in benthic communities.

The current study was conducted in Kongsfjord, which is an Arctic glacial fjord situated in the Svalbard archipelago. Glacier activity produces clear environmental gradients of salinity, turbidity, sedimentation, organic matter supply, and sediment stability (Hop et al. 2002, Svendsen et al. 2002). Previous analyses of a full set of benthic data identified to the species level demonstrated gross changes of benthic composition and diversity along the glacial disturbance gradient (Włodarska-Kowalczuk \& Pearson 2004, WłodarskaKowalczuk et al. 2005). The objective of the current study was to examine if these clear patterns of natural benthic distribution and diversity evidenced at the species level can be detected when the level of taxonomic resolution is lowered or only a selected group of animals is analyzed. We also aimed to compare the current results to published tests of performance of surrogacy analyses in other natural and anthropogenic benthic patterns in order to detect common effects and to learn if, as Warwick (1988a) hypothesized, analyses at lower taxonomic resolution would be ineffective in studies of natural environmental variability in contrast to pollution gradients.

\section{MATERIALS AND METHODS}

Kongsfjord is an open fjord, $26 \mathrm{~km}$ in length, situated on the northwestern coast of Spitsbergen, the main island of the Svalbard archipelago $\left(79^{\circ} \mathrm{N}, 12^{\circ} \mathrm{E}\right.$; Fig. 1). Depths rarely exceed $350 \mathrm{~m}$. Despite its location at a high latitude, the fjord is sub-Arctic in character, as its hydrology is influenced by the warm Atlantic waters of the West Spitsbergen Current (Svendsen et al. 2002). Three tidal glaciers terminate in the fjord waters. Kongsbreen, situated in the innermost part of the fjord, is the most active glacier in the Svalbard archipelago (Lefauconnier et al. 1994); each summer its melt waters transport about $2.6 \times 10^{5} \mathrm{~m}^{3}$ of mineral material into the fjord (Elverhoi et al. 1983). Concentrations and sedimentation rates of suspended inorganic particles decrease by about 2 orders of magnitude from the Kongsbreen glacial bay (300 to $500 \mathrm{mg} \mathrm{dm}^{-3}$ and $800 \mathrm{~g} \mathrm{~m}^{-2}$ $\mathrm{d}^{-1}$, respectively) to the central part of the fjord ( $20 \mathrm{mg}$ $\mathrm{dm}^{-3}$ and $25 \mathrm{~g} \mathrm{~m}^{-2} \mathrm{~d}^{-1}$; Elverhoi et al. 1980, Zajacz- 
kowski 2000). High amounts of mineral suspensions strongly decrease the penetration of light into the water column. The highest water transparency is observed at the mouth of the fjord, where the euphotic zone extends down to a depth of $33.5 \mathrm{~m}$. The euphotic zone thickness decreases to $6-25 \mathrm{~m}$ in the central fjord and down to only $0.3 \mathrm{~m}$ in the glacial bay (Svendsen et al. 2002). The sediments in the deeper sublittoral zone of the fjord (below $30 \mathrm{~m}$ ) are composed of silt, with some sandy and clayey admixtures (Włodarska-Kowalczuk \& Pearson 2004). Sediments of the inner and outer basins are similar in terms of their granulometry, but differ with regard to their deposition rates and stability (Elverhoi et al. 1983). The sediment accumulation rate decreases by about 1 order of magnitude from the glacial bay (20000 $\mathrm{g} \mathrm{m}^{-2} \mathrm{yr}^{-1}$ ) to the central part of the fjord (1800 to $3800 \mathrm{~g} \mathrm{~m}^{-2} \mathrm{yr}^{-1}$ ) and, again, by another order of magnitude towards the outer fjord $\left(200 \mathrm{~g} \mathrm{~m}^{-2} \mathrm{yr}^{-1}\right.$; Svendsen et al. 2002). In glacial bays, the deposited material is not compacted and is frequently resuspended by iceberg scouring, sediment slides, and gravity flows (Dowdeswell 1987, Syvitski et al. 1987), and the stability of the sediments increases towards the central parts of the fjord. The biotic characteristics of the Kongsfjord ecosystem have been summarized by Hop et al. (2002), while its physical features have been described in detail by Svendsen et al. (2002).

Eighty van Veen grab samples (of $0.1 \mathrm{~m}^{2}$ sample area) were collected at 30 stations located throughout the fjord at depths ranging from 38 to $380 \mathrm{~m}$ (Fig. 1). Material was collected in July of 1997 and 1998 during cruises of RV 'Oceania'. The samples were sieved through a $0.5 \mathrm{~mm}$ mesh and fixed in buffered $4 \%$ formaldehyde. The macrofauna was sorted, counted, and identified to the lowest possible taxonomic level. Non-metric multidimensional scaling (nMDS) of Bray-Curtis similarities computed using the species abundance data matrix permitted us to distinguish 4 groups of samples that indicated a sequence of 4 faunal associations located along the fjord axis: (1) GLAC, located in the Kongsbreen glacial bay; (2) TRANS, at the edge of the Kongsbreen glacial bay and close to Blomstrandbreen; (3) CENTR, in the central basin; (4) ENTR, at the fjord entrance (Fig. 1; Włodarska-Kowalczuk \& Pearson 2004). The associations were clearly separate at the level of both dominant numbers and entire species lists; this was documented by the analyses of data subjected to a range of transformations (from no transformation to presence/ absence data; Włodarska-Kowalczuk \&
Pearson 2004). There were significant differences in the diversity of the 4 associations that could be related to glacial disturbance level (Włodarska-Kowalczuk et al. 2005).

Eight SURROGATE data matrices were constructed from the BASIC matrix of species abundance in the samples: 5 aggregation matrices (species abundance aggregated to the levels of genus, family, order, class, and phylum) and 3 selected taxa matrices (extracted data for Polychaeta, Mollusca, and Crustacea-the most dominant taxa).

Bray-Curtis similarities of samples were computed based on data subjected to a sequence of transformations (gradually decreasing the influence of dominant taxa): none, square root, and presence/absence. The relationships between the similarities within the BASIC data matrix and the 8 SURROGATE data matrices were examined using Spearman's rank correlation coefficient computed between corresponding elements of the relevant matrices. The significance of correlation was determined with the Monte Carlo permutation procedure using the RELATE routine of the PRIMER program (Clarke \& Warwick 1994). The multivariate patterns in the similarity matrices were compared using the method by Somerfield \& Clarke (1995), where rank correlations, calculated between pairs of similarity matrices, become the elements of a second-stage similarity matrix, which is then used as an input matrix for second-stage nMDS ordination. In such ordination, each symbol represents a similarity

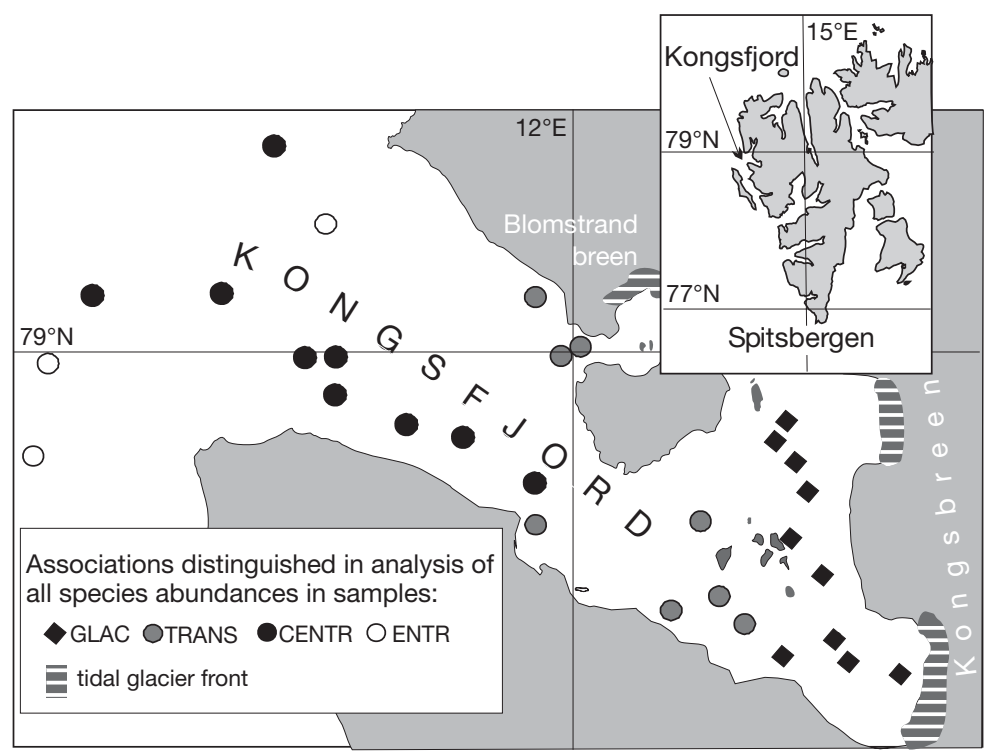

Fig. 1. Locations of Kongsfjord and sampling stations. Symbols represent associations distinguished in multivariate analysis of all species abundances in samples as described by Włodarska-Kowalczuk \& Pearson (2004). GLAC: located in the Kongsbreen glacial bay; TRANS: at the edge of the Kongsbreen glacial bay and close to Blomstrandbreen; CENTR: in the central basin; ENTR: at the fjord entrance 
matrix and the relative distances between symbols indicate how similar they are. Thus, the patterns in a number of similarity matrices from each investigation can be compared simultaneously (e.g. to study the relative effects of transformation or the use of a data subset on multivariate patterns).

The current study also tested whether the basic pattern documented by the analysis of similarities within the BASIC data matrix (the separation of 4 associations: GLAC, TRANS, CENTR, and ENTR) can be perceived at the higher taxonomic levels or within selected taxonomic groups. Formal significance tests for differences between groups of samples belonging to the 4 associations were performed using the 1-way ANOSIM permutation test (Clarke \& Green 1988). The ANOSIM procedure was applied to Bray-Curtis similarities of square-root transformed data of all SURROGATE matrices.

Richness, defined as the number of taxa in a sample $(S)$, taxonomic diversity measured with the ShannonWiener diversity $\log _{\mathrm{e}}$ based index $(H)$, and the Hurlbert rarefaction index for 50 individuals (ES[50]), as well as the evenness of distribution of individuals between taxa expressed by the Pielou index $(J)$, were calculated for BASIC and all SURROGATE data matrices. Relationships between values of diversity metrics calculated using BASIC and all SURROGATE data matrices were explored using non-parametric Spearman $R$ rank correlation, since, even after data transformation, the normality of the data distribution could not be assessed.

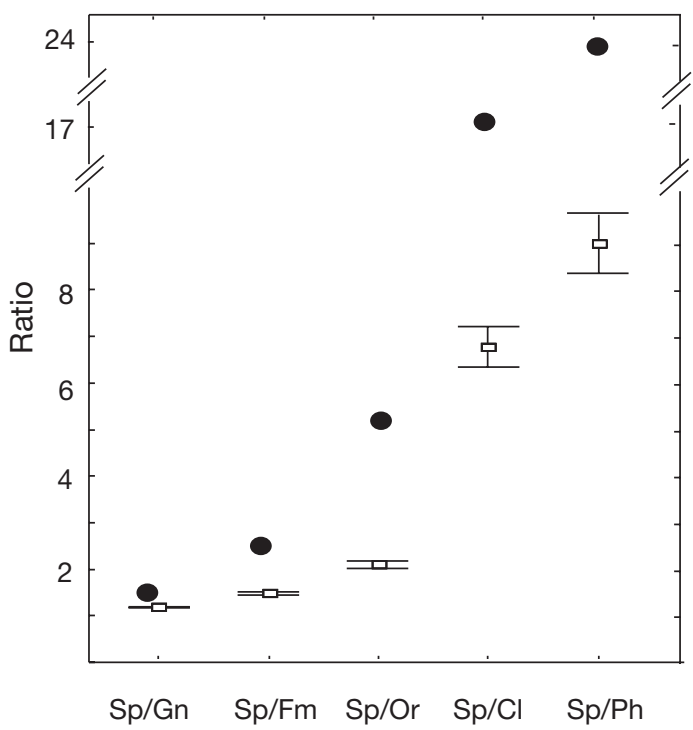

Fig. 2. Ratio of numbers of species ( $\mathrm{Sp}$ ) to numbers of genera $(\mathrm{Gn})$, families $(\mathrm{Fm})$, orders $(\mathrm{Or})$, classes $(\mathrm{Cl})$, and phyla $(\mathrm{Ph})$.

-: ratio of total number of species to total number of relevant taxa found in all studied material; $\square$ : mean $( \pm 0.95$ confidence intervals) ratio in samples
The persistence of patterns of richness detected at the species level (differences between the 4 faunal associations) with lowering levels of taxonomic resolution or within selected groups was examined. One-way analyses of variance (ANOVA) were used to check for significant differences in the numbers of taxa per sample between associations studied using data aggregated to family and order levels and using the Mollusca data set. The numbers of families were log transformed prior to analyses to assess the homogeneity of variance. The non-parametric Kruskal-Wallis test was used in all other cases, since, even after transformations, the normality of data distributions or the homogeneity of variance could not be assessed.

The data analyses were performed using the Primer package V. 6 (Clarke \& Green 1988) and the Statsoft software Statistica V. 6.

\section{RESULTS}

The fauna was represented by 38397 individuals belonging to 221 species, 159 genera, 90 families, 41 orders, 13 classes, and 9 phyla. The 108 polychaete species were the most prevalent, comprising almost $50 \%$ of all the species and were followed by crustaceans (46 species) and molluscs (39 species). These 3 groups also dominated numerically, with Polychaeta comprising from 20 to $95 \%$ of all the individuals in the samples, Mollusca comprising from 3 to $66 \%$, and Crustacea comprising from 1 to $15 \%$. The ratio of the number of species to the number of higher taxa in the samples was very low for genera (mean \pm SD: $1.1 \pm$ $0.1)$, families $(1.4 \pm 0.2)$, and orders $(2.0 \pm 0.4)$ and much higher for classes $(6.7 \pm 1.9)$ and phyla $(8.9 \pm 2.8)$ (Fig. 2).

\section{Patterns of distribution}

The low stress values on all the 2-stage ordination plots indicate the excellent bidimensional representation of multidimensional space (Figs. $3 \& 4$ ). The genus aggregated matrix was most similar to the BASIC matrix, especially when the square-root-transformed or presence/absence data were considered (Fig. 3B,C). When all the possible combinations of higher taxon aggregations/data transformations were treated together, 2 very tight groups of matrices were formed: (1) matrices for presence/absence data of species, genera, and families and (2) matrices for untransformed and double-root-transformed data of species, genera, families, and orders (Fig. 3D). No matter which data transformation was applied, both the class and phylum level of identification were well separated from 

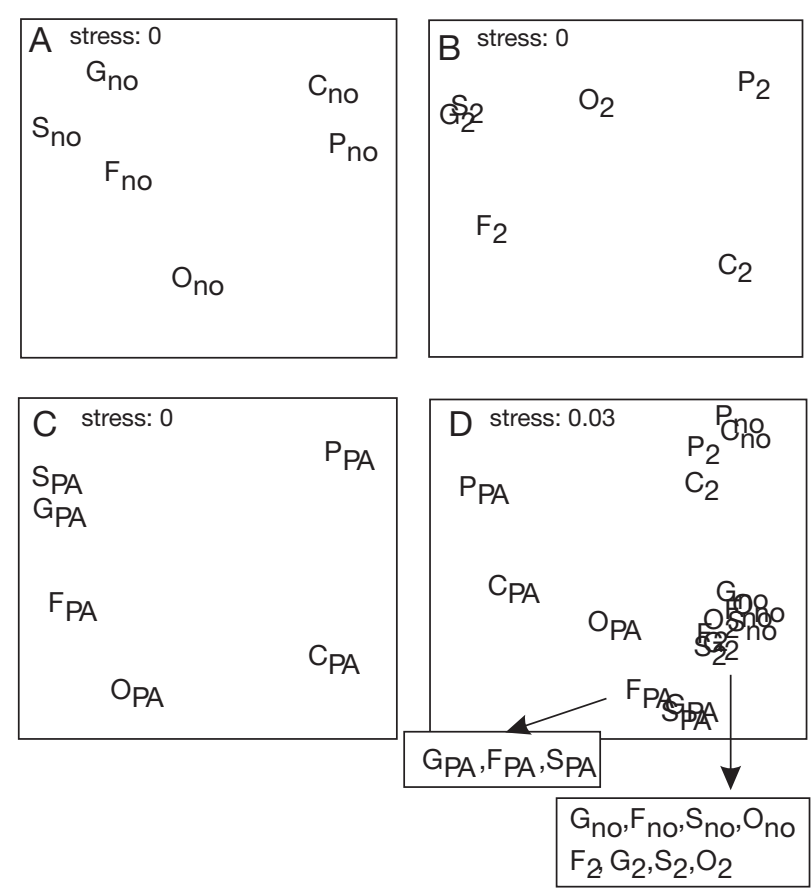

Fig. 3. 'Second-stage' non-metric multidimensional scaling (nMDS) ordination of inter-matrix rank correlations between BASIC data matrix (S: all taxa identified to species level) and SURROGATE matrices constructed by the aggregation of species data into higher taxonomic levels: genera $(\mathrm{G})$, families $(\mathrm{F})$, orders (O), classes (C), and phyla (P). (A) Untransformed data (no), (B) square-root transformed data (2), (C) presence/absence data (PA), and (D) all combinations of matrices/transformations

the data analyzed at a higher taxonomic resolution. Polychaete-based-untransformed and double-roottransformed SURROGATE matrices grouped most tightly with the BASIC matrix when the selected group matrices were considered (Fig. 4). The similarity of polychaete and BASIC matrices was lower in the case of presence/absence data (Fig. 4C,D).

The Spearman rank correlations were significant for all studied SURROGATE matrices, but exceeded 0.8 only for matrices based on extracted polychaetes or species aggregated to genus, family, and order levels (with the exception of presence/absence order level data) (Fig. 5).

The distribution of samples belonging to the 4 associations is visually almost identical on nMDS plots created for data analyzed at the species, genus, and family levels (Fig. 6). High values of the ANOSIM $R$ statistic confirmed clear separation of the associations ( $R=0.90$ for species data, 0.89 for genera, and 0.87 for families). The ANOSIM test separated the associations in polychaetes $(R=0.89)$ and data aggregated to the order level $(R=0.83)$ matrices equally well, but the patterns of sample distribution on the relevant nMDS


Fig. 4. 'Second-stage' nMDS ordination of inter-matrix rank correlations between BASIC data matrix ( $\mathrm{S}$ : all taxa identified to species level) and SURROGATE matrices constructed by the extraction of data from selected taxonomic groups: Polychaeta $(\mathrm{P})$, Mollusca (M), and Crustacea (C). (A) Untransformed data (no), (B) square-root transformed data (2), (C) presence/absence data (PA), and (D) all combinations of matrices/transformations

plots were slightly disturbed when compared to a plot computed for the BASIC data matrix (Fig. 6). The low values of the ANOSIM $R$ statistic (and a visual inspection of the nMDS plots) indicated that the associations were not separable when data were aggregated to

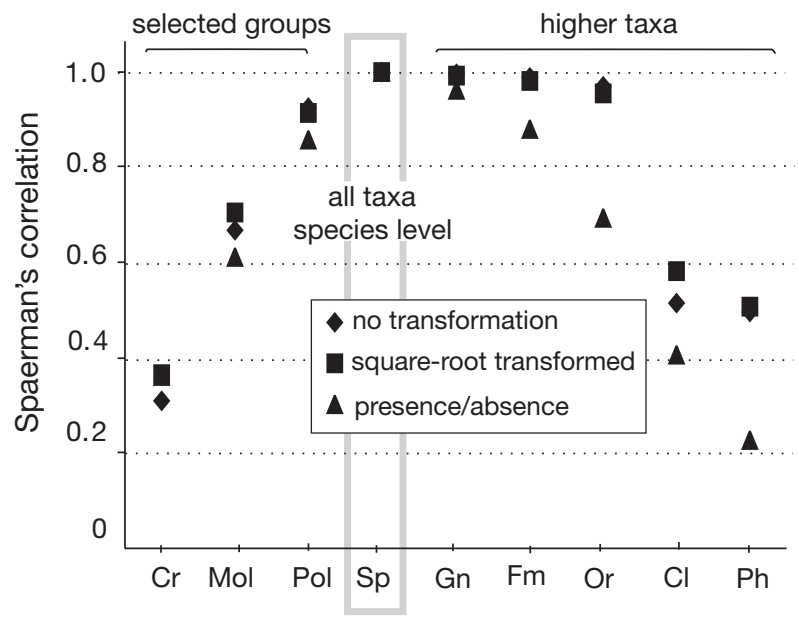

Fig. 5. Spearman rank correlation between a matrix of similarity of the BASIC dataset comprising all taxa identified to the species level (Sp) and SURROGATE matrices constructed for selected groups: Crustacea (Cr), Mollusca (Mol), and Polychaeta (Pol), and for higher taxonomic levels: genera (Gn), families $(\mathrm{Fm})$, orders $(\mathrm{Or})$, classes $(\mathrm{Cl})$, and phyla $(\mathrm{Ph})$. All correlations were significant at $\mathrm{p}<0.05$ 

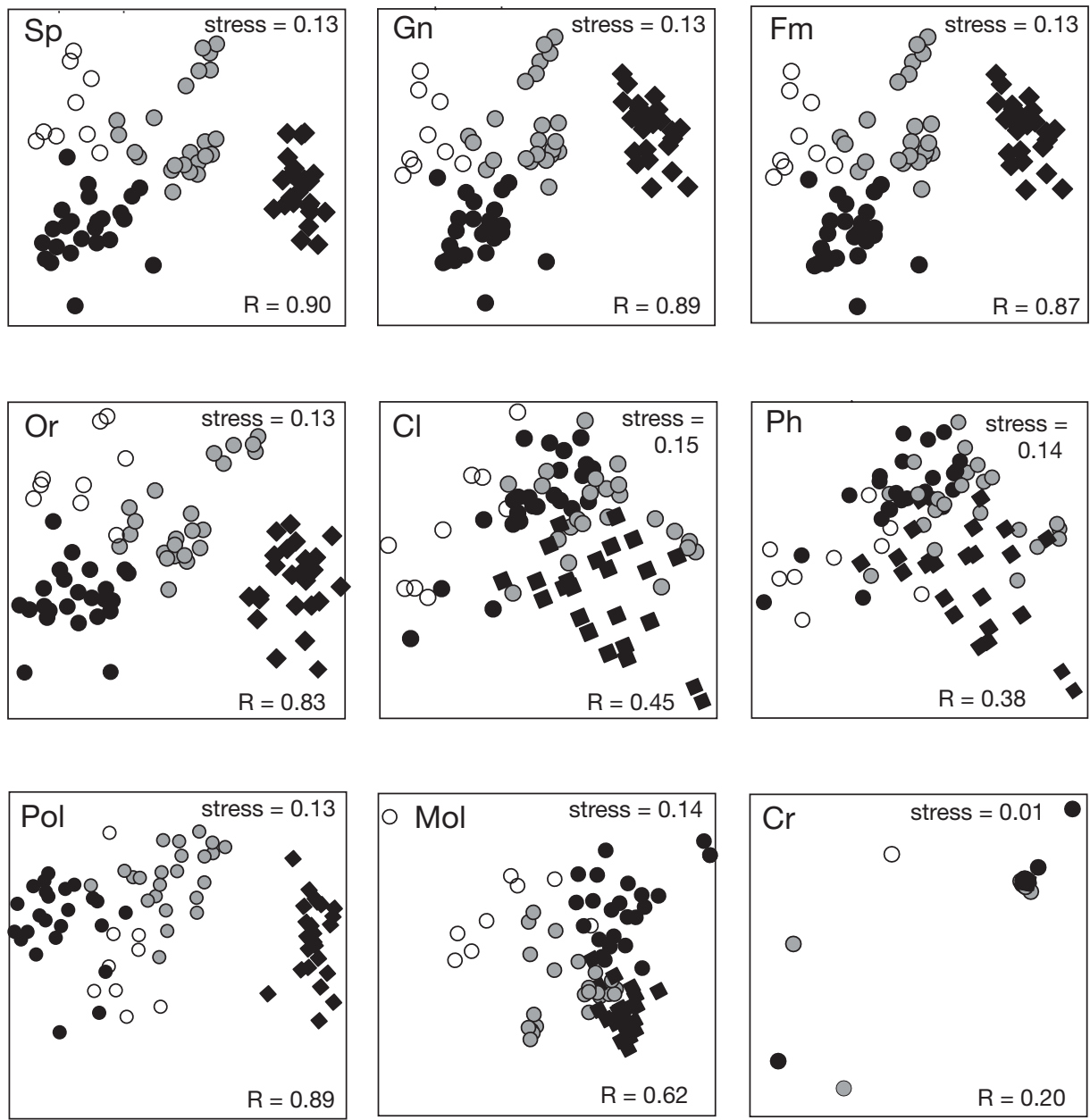

Fig. 6. nMDS plots of Bray-Curtis similarities of benthic composition in samples. Data were square-root transformed prior to analyses. The plots were constructed using the BASIC dataset comprising all taxa identified to the species level (Sp) and SURROGATE matrices constructed for selected groups: Crustacea (Cr), Mollusca (Mol), and Polychaeta (Pol), and for higher taxonomic levels: genera (Gn), families (Fm), orders (Or), classes $(\mathrm{Cl})$, and phyla (Ph). Symbols represent associations distinguished in the analyses of the BASIC dataset (as described by Włodarska-Kowalczuk \& Pearson 2004): ( ) GLAC, (O) TRANS, (๑) CENTR,

(O) ENTR. R: ANOSIM statistics for global tests of differences between associations ( $p=0.001$ in all cases)

class or phylum level or only molluscs or crustaceans were analyzed (Fig. 6).

\section{Patterns of diversity}

All diversity measures computed using genera and families were very strongly correlated to those calculated for species data $(R>0.95, \mathrm{p}<0.05$; Fig. 7$)$. The correlations were also high in cases of orders and extracted annelids $(R>0.75, \mathrm{p}<0.05)$. The correlations for classes and phyla were still significant for $S$ and ES[50], but no significant correlation at $\mathrm{p}<0.05$ was detected for $H$ and $J$ (Fig. 7). While mollusc-based diversity measures were moderately correlated to the whole macrobenthic community diversity $(R \approx 0.5)$, crustacean diversity variability did not match that of the BASIC dataset (Fig. 7).

The species richness patterns observed along the glacial disturbance gradient (lowest mean diversity in near glacial samples-association GLAC $;$ maximum mean diversity in the transitional zone-association TRANS) persisted when taxonomic resolution was lowered to the genus, family, and order levels (Fig. 8). The polychaete richness was the lowest in association GLAC, but it did not differ between the remaining groups of samples. There was no cline of diversity of molluscs in near-glacial areas, while the peak of diversity in the transitional zone was very pronounced. Crustacean species numbers did not vary between the 4 associations distinguished by BASIC dataset multivariate analyses (Fig. 8). 


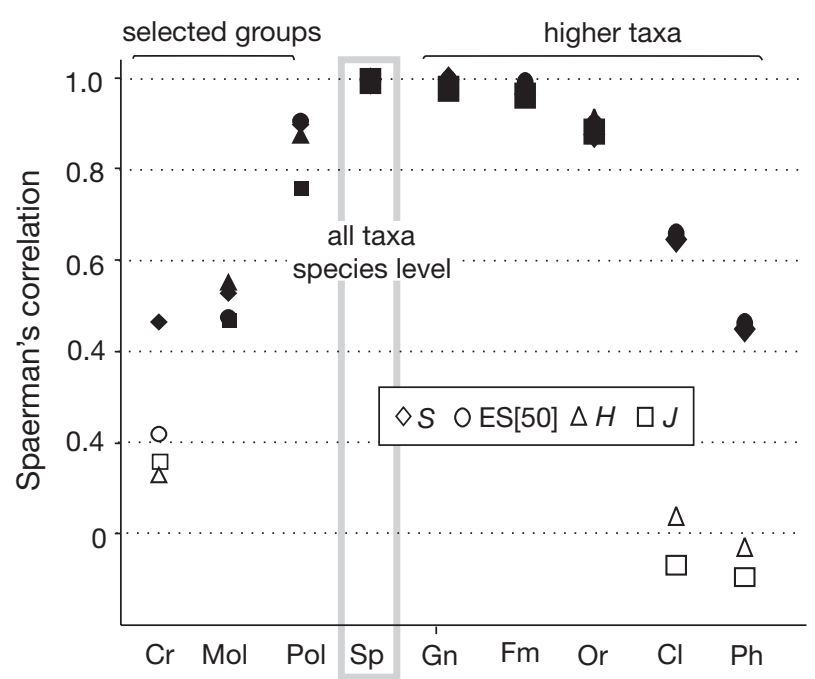

Fig. 7. Spearman rank correlations between diversity measures ( $S$ : number of taxa per sample; ES[50]: Hurlbert index; $H$ : Shannon-Wiener index; J: Pielou index) of BASIC dataset comprising all taxa identified to species level (Sp) and SURROGATE matrices constructed for selected groups: Crustacea $(\mathrm{Cr})$, Mollusca (Mol), and Polychaeta (Pol), and for higher taxonomic levels: genera (Gn), families (Fm), orders (Or), classes $(\mathrm{Cl})$, and phyla $(\mathrm{Ph})$. Solid symbols indicate significant correlations (at $\mathrm{p}<0.05)$

\section{DISCUSSION}

The results of the current study demonstrate that there is a strong correlation between the natural benthic diversity and distribution patterns observed at the level of species, genus, and family. Little information is lost even if the organisms are only identified to the order level. Similarly high correlations are obtained when annelid species are extracted from the BASIC dataset and analyzed separately. The current results indicate that intermediate taxonomic levels or a selection of annelids are possible surrogates sufficient to document the benthic response to naturally produced disturbances or environmental change.

It is intuitively reasonable that the higher taxon richness may be a good predictor of the patterns of species richness when the ratio of the number of species to the number of relevant taxa is close to 1 (Doerries \& Van Dover 2003). The low ratios observed in the current samples for genera (1.3) and families (1.9) explain the excellent performance of the 2 taxa in the surrogacy tests. The patterns of orders (with the ratio of numbers of species/numbers of orders equal to 2.0) were still significantly correlated to patterns of species, although with lower precision. For both classes and phyla the species/higher taxa ratio increased and the predictive potential dropped dramatically. Giangrande et al. (2005) claimed that taxonomic sufficiency can work only in brackish waters, where very few species belonging to different groups are able to thrive and sympatric speciation is reduced or absent due to short evolutionary time. They used the species/higher taxa ratio as a measure of the applicability of taxonomic sufficiency (TS) to different datasets (without actually testing it) and predicted that in hard substrates, where the number of species/number of families ratio often exceeds 6, TS cannot work. The high species/higher taxa ratio, however, does not directly induce ineffective TS performance (e.g. compare the high TS potential of the phylum level with the very high species/ phyla ratio in several pollution studies cited in Table 1).

The patterns of distribution and diversity of families matched perfectly with those observed at the species level in the current study. A comparison of several other TS studies indicates that the family level is the threshold level sufficient to describe the patterns of benthic diversity and distribution in all reported combinations of possible impacts/habitats (Table 1). The TS performance of higher taxonomic levels (orders, classes, and phyla) varied in different studies (Table 1). As noted by Warwick (1993), species variability can be easily translated into family distribution, as a family usually represents a relatively uniform group of animals of consistent basic functional traits such as feeding, mobility, or spatial behavior characteristics (as described, for example, for polychaete worms by Fauchald \& Jumars 1979) and so may react to environmental fluctuations in a similar way.

Warwick (1988a) suggested that higher taxonomic levels can reflect pollution gradients, but not natural environmental variability, the latter driving species replacement rather than shifts in major taxa composition. The hierarchical-response-to-stress theory suggests that as stress increases, first adaptability of individuals, followed by species, genus, etc. is exceeded. Impacts resulting from increasing stress are accumulated at increasingly higher taxononimic levels. As disturbance increases, the faunal gradients become stronger and, therefore, impacts can be detected with lower taxonomic resolution. The few published TS studies that focused on natural benthic patterns and the only one that addressed soft-bottom macrofauna (De Biasi et al. 2003) contrast with a number of soft-bottom anthropogenic impact studies (Table 1). In contrast to Warwick's (1988a) predictions, the good performance of TS was clearly evidenced by a few published studies of natural benthic variability, although the natural patterns observed at the species level have never persisted at the coarsest taxonomic level (classes and phyla), as has been documented in several anthropogenic disturbance studies (Table 1). 

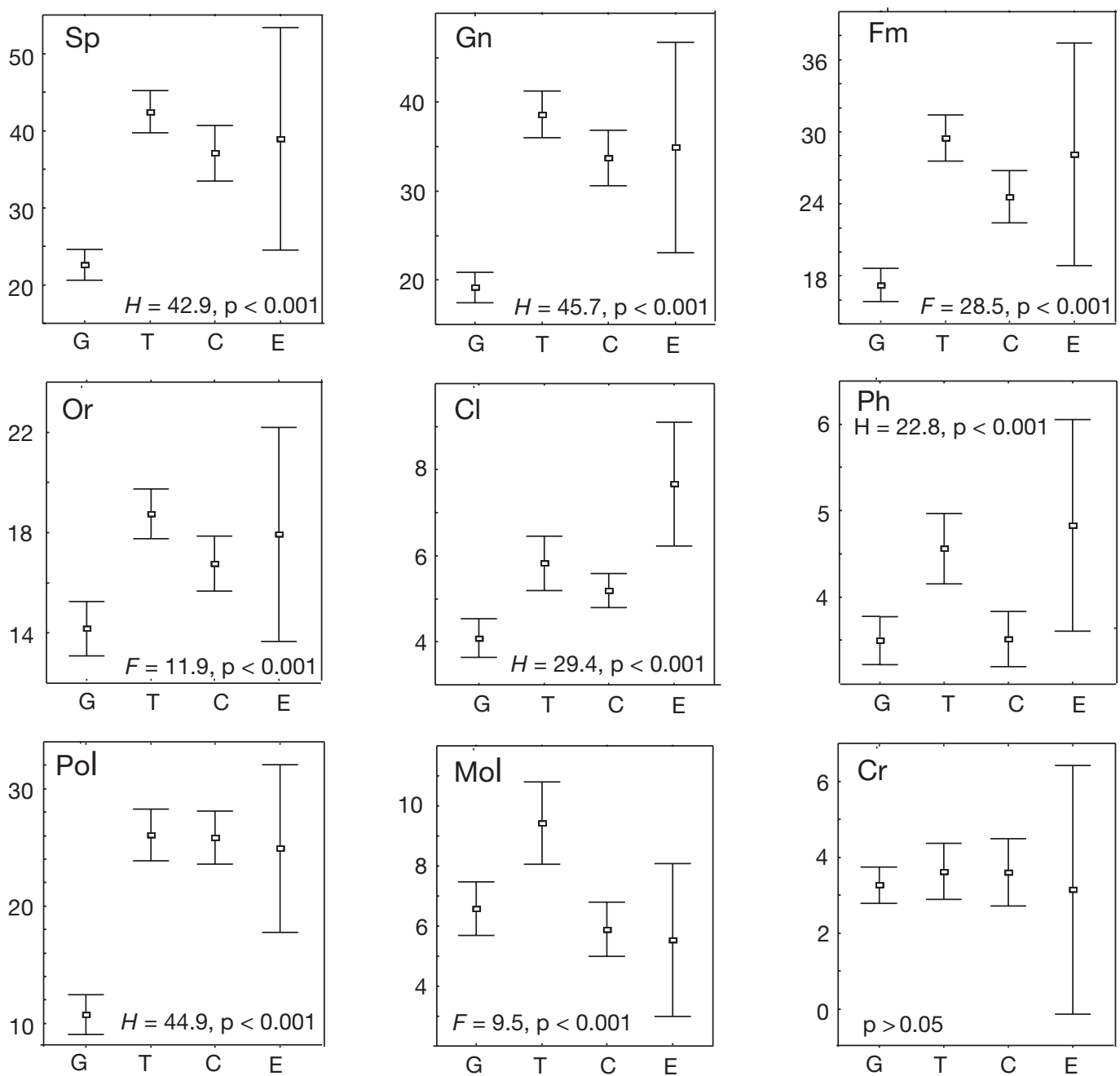

Fig. 8. Taxonomic richness (number of taxa per sample) in 4 benthic associations distinguished by multivariate analyses of all species abundances in samples (as described in Włodarska-Kowalczuk \& Pearson 2004). G: GLAC; T: TRANS; C: CENTR; E: ENTR. Means \pm 0.95 confidence intervals are plotted. The plots were constructed using the BASIC dataset comprising all taxa identified to species level (Sp) and SURROGATE matrices constructed for selected groups: Crustacea (Cr), Mollusca (Mol), and Polychaeta $(\mathrm{Pol})$, and for higher taxonomic levels: genera (Gn), families (Fm), orders (Or), classes $(\mathrm{Cl})$, and phyla $(\mathrm{Ph})$

The taxonomic sufficiency approach has obvious advantages; the cost and time savings may be tremendous, for example, identification to the family or order can reduce costs by 50 and $80 \%$, respectively (Ferraro \& Cole 1995) and sample processing time can be reduced by 40 and $76 \%$, respectively (Thompson et al. 2003). In deep-sea surveys, identification to the genus level only requires about half of the time needed to identify individuals to the species level (Doerries \& Van Dover 2003). There are too few taxonomists to process all the work that needs to be done, especially within the lesser-known groups. For example, there are presently $<10$ specialists worldwide who are able to identify sipunculan worms properly (Murina et al. 1999). Not only is it easier and cheaper to train personnel to sort to taxonomic levels higher than species, the risk of potential taxonomic classification error is also lower at a higher level of identification (Dauvin et al. 2003). Higher groups are often more clearly defined than are species (Gaston 2000), which means that higher taxa identifications can be more reliable and consistent across different laboratories (see e.g. Ellis \& Cross [1981] for identification accuracy tests performed at 9 established marine benthic laboratories). Finally, the fauna in several remote or poorly investigated regions across the world's oceans has yet to be described, and species level identifications are not possible without the concerted effort of a team of highly specialized taxonomic experts (Bouchet et al. 2002). 
Table 1. Taxonomic sufficiency documented for natural and anthropogenically induced benthic patterns. The taxonomic level is regarded as sufficient (+) when $R \geq 0.75$. In distribution studies, $R$ stands for a Spearman rank correlation of relevant similarity matrices. In diversity studies, $R$ stands for the correlation between numbers of species and the numbers of relevant taxa in the samples. When possible, the ratio of the number of species to the number of relevant higher taxa in a given study is calculated and presented in parentheses. A dot indicates no analysis conducted at a relevant taxonomic level

\begin{tabular}{|c|c|c|c|c|c|c|}
\hline Type of study & Genus & Family & Order & Class & Phylum & Source \\
\hline \multicolumn{7}{|l|}{ Soft bottom-natural patterns } \\
\hline Glacial sedimentation gradient & $+(1.4)$ & $+(2.5)$ & $+(5.3)$ & $-(17.0)$ & $-(24.6)$ & Present study \\
\hline Estuarine gradient & $+(1.2)$ & $+(1.5)$ & $-(3.5)$ & $-(11.4)$ & $-(19.0)$ & De Biasi et al. (2003) \\
\hline \multicolumn{7}{|l|}{ Soft bottom-anthropogenic disturbance } \\
\hline Dredgings disposal & + & + & . & . & + & Somerfield \& Clarke (1995) \\
\hline Heavy metal contamination & + & + & . & . & + & Somerfield \& Clarke (1995) \\
\hline Organic pollution $^{\mathrm{a}}$ & & $+(2.1)$ & . & . & $-(13.6)$ & Warwick (1988a) \\
\hline Oil drilling pollution & $+(1.1)$ & $+(1.5)$ & $+(3.7)$ & $+(8.7)$ & $+(15.6)$ & Olsgard et al. (1997) \\
\hline Sewage discharge & + & + & + & - & . & Thompson et al. (2003) \\
\hline Oil drilling pollution & + & + & $+/-$ & - & - & Olsgard \& Somerfield (2000) \\
\hline Pulp-mill effluent ${ }^{a}$ & . & $+(2.6)$ & . & . & $+(12.8)$ & Warwick (1988b) \\
\hline Sewage sludge ${ }^{a}$ & . & $+(1.8)$ & . & . & $+(8.3)$ & Warwick (1988b) \\
\hline Hydrocarbon pollution $^{\mathrm{a}}$ & . & . & . & . & + & Warwick (1988b) \\
\hline Heavy metal contamination & $+(1.3)$ & $+(2.2)$ & $+(5.1)$ & $-(15.5)$ & . & Vanderklift et al. (1996) \\
\hline Fish farming effects ${ }^{\mathrm{b}}$ & + & + & + & + & + & Lampadariou et al. (2005) \\
\hline \multicolumn{7}{|l|}{ Other habitats } \\
\hline Kelp associated fauna-domestic effluents outfall & . & $+(1.9)$ & $+(5.8)$ & $+(12.7)$ & $+(21.6)$ & Smith \& Simpson (1993) \\
\hline Pebble-sand beaches-estuarine gradient & . & + & . & - & - & Dethier \& Schoch (2006) \\
\hline Deep-sea mussel beds-diversity assessment & $+(1.2)$ & $+(1.7)$ & $+/-$ & . & . & Doerries \& Van Dover (2003) \\
\hline Hard bottom-estuarine gradient ${ }^{\mathrm{a}}$ & . & $+(1.4)$ & . & . & . & Urkiaga-Alberdi et al. (1999) \\
\hline
\end{tabular}

Based on the extracted abundances of 3 taxonomic groups (Polychaeta, Crustacea, and Mollusca), the current analyses showed that polychaete diversity and distribution patterns were best correlated to those of the whole dataset. This is certainly linked directly to the high dominance of this group. Polychaetes comprised almost $70 \%$ of all the sampled macrobenthic individuals; thus, the variability of polychaete populations must have strongly influenced the patterns observed for the whole benthic community. Annelid diversities and abundances drop dramatically when the worms are exposed to glacier-derived mineral sedimentation (Kendall 1994). The suspension-feeding worms are eliminated from near glacial areas as the high mineral sedimentation can clog the feeding and respiratory organs. Tube-dwelling polychaetes are also very sensitive to sediment instabilities and high sedimentation, as these can bury the tubes, impede irrigation, and result in suffocation. The mobile deposit-feeding polychaetes are confronted with the low amount of available organic matter, as the high turbidity reduces primary production in the water column and organic matter sedimenting to the bottom is diluted by the high inorganic sediment load (Włodarska-Kowalczuk et al. 2005). Molluscs respond to glacial disturbances differently, as protobranch bivalves seem to cope very well with both sediment instabilities and the dilution of organic matter and occur in large numbers in glacial bays (WłodarskaKowalczuk et al. 1998, Włodarska-Kowalczuk \& Pearson 2004). Yoldiid bivalves are well suited to resisting glacial sedimentation, as they are relatively mobile thanks to a large and muscular foot, possess an efficient mechanism of elimination of pseudofaeces from the mantle cavity, and can efficiently sort the organic particles collected with use of long palp proboscides. Therefore, mollusc diversity does not decline, and its abundance can even increase as proximity to the glacier increases (Włodarska-Kowalczuk 2007). The maximum mollusc richness in the TRANS association was translated into a peak of diversity for the whole macrobenthic community, but no similar pattern was observed when polychaetes alone were analyzed (Fig. 8). Crustacean variability was least correlated to the overall macrobenthic community patterns observed in the current study. The numbers of crustacean species did not vary between the 4 faunal associations identified along the glacier disturbance gradient, which suggests that environmental factors other than glacial sedimentation drive the spatial variability 
patterns of this group of animals. The different response of the crustaceans may also derive from the higher relative mobility of this group (as compared to polychaetes or molluscs).

Olsgard \& Somerfield (2000) suggested that polychaetes are a potentially good surrogate taxon as they exhibit relatively large environmental flexibility and high diversity of feeding and functional guilds, reproductive strategies, and levels of pollution resistance. In a North Sea oil field study, polychaetes were good predictors of the macrobenthic response to severe pollution gradients, but were not correlated to natural benthic variability at unimpacted sites. In a benthic study of Newfoundland fjordic sediments conducted by Quijon \& Snelgrove (2005), polychaete diversities explained $75 \%$ of the variation in all macrobenthic species collected on mud, but only $22 \%$ in samples collected on a sandy bottom. Other studies report excellent surrogate performance of molluscs (e.g. the diversity assessment of rocky shore macrofauna by Smith [2005] and the study of kelp holdfast-associated fauna by Anderson et al. [2005]). The predictive potential of selected groups in macrobenthic investigations seems to depend on the nature of stress-generating factors and habitat/community type. This suggests that surrogates based on selected taxonomic groups should be applied with much caution, especially if the predictive value of a given group in a studied locality has not been tested in a pilot study.

\section{CONCLUSIONS}

The identification of all animals to the species level certainly provides the most comprehensive information on benthic population variability. Thus, it remains the preferred approach; however, if it is impossible and a surrogate method has to be chosen, then the TS approach is recommended over analyses limited to just one taxonomic group. It has been demonstrated that, along a natural disturbance gradient, polychaetes mirrored patterns of all species distribution and diversity as well as the intermediate taxonomic levels (genera, families, orders). Nevertheless, we contend that more information on the variability of responses to environmental factors is lost by focusing on only a fraction of the macrobenthic community than by lowering the taxonomic resolution. Moreover, the performance of selected taxonomic groups as surrogates for the whole macrobenthic community varies significantly across different habitat and environmental regimes. The TS approach seems to produce far more consistent results when applied to different situations/datasets. In all of the studies summarized in Table 1, the family-level patterns were good predictors of species-level varia- bility. This suggests that families could be used as a reliable measure of benthic response to environmental gradients when species identifications are not available. Certainly, when possible, the material should be archived so that lower level taxonomic identification could be conducted in the future. More studies covering a wide range of habitats and environmental drivers are needed to confirm the general applicability of family TS in marine benthic ecology. There might be several cases in which TS does not work, and the publication of such examples should be encouraged vigorously to ensure that another 'file drawer problem' (i.e. strong negative bias against publishing norelationship results; Csada et al. 1996, Gaston 2000) does not occur.

Acknowledgements. The study was completed thanks to funding provided by Grant N304 034 31/1202 from the State Committee for Scientific Research. The authors acknowledge the support of the MarBEF Network of Excellence 'Marine Biodiversity and Ecosystem Functioning', which is funded by the Sustainable Development, Global Change and Ecosystems Programme of the European Community's Sixth Framework Programme (Contract No. GOCE-CT-2003-505446). This publication is Contribution Number MPS-07041 of Mar$\mathrm{BEF}$ and is a contribution to the MarBEF responsive mode program ArctEco.

\section{LITERATURE CITED}

Anderson MJ, Diebel CE, Blom WM, Landers TJ (2005) Consistency and variation in kelp holdfast assemblages: spatial patterns of biodiversity for the major phyla at different taxonomic resolutions. J Exp Mar Biol Ecol 320: $35-56$

Bouchet P, Louzet P, Maestrati P, Heros V (2002) Assessing the magnitude of species richness in tropical marine environments: exceptionally high numbers of molluscs at a New Caledonia site. Biol J Linn Soc 75:421-436

Clarke KR, Green RH (1988) Statistical design and analysis for a 'biological effects' study. Mar Ecol Prog Ser 46:213-226

Clarke KR, Warwick RM (1994) Changes in marine communities: an approach to statistical analysis and interpretation. Natural Environment Research Council, Plymouth Marine Laboratory, Plymouth

Csada RD, James PC, Espie RHM (1996) The 'file drawer problem' of nonsignificant results: Does it apply to biological research? Oikos 76:591-593

Dauvin JC, Gesteira JLG, Fraga MS (2003) Taxonomic sufficiency: an overview of its use in the monitoring of sublittoral benthic communities after oil spills. Mar Pollut Bull 46:552-555

De Biasi AM, Bianchi CN, Morri C (2003) Analysis of macrobenthic communities at different taxonomic levels: an example from an estuarine environment in the Ligurian Sea (NW Mediterranean). Estuar Coast Shelf Sci 58:99-106

Dethier MN, Schoch GC (2006) Taxonomic sufficiency in distinguishing natural spatial patterns on an estuarine shoreline. Mar Ecol Prog Ser 306:41-49

Doerries MB, Van Dover CL (2003) Higher-taxon richness as a surrogate for species richness in chemosynthetic communities. Deep-Sea Res I 50:749-755 
Dowdeswell JA (1987) Processes of glaciomarine sedimentation. Prog Phys Geogr 11:52-90

Ellis D (1985) Taxonomic sufficiency in pollution assessment. Mar Pollut Bull 12:459

Ellis DV, Cross SF (1981) A protocol for inter-laboratory calibrations of biological species identifications (ring tests). Water Res 15: 1107-1108

Elverhoi A, Liestol O, Nagy J (1980) Glacial erosion, sedimentaion and microfauna in the inner part of Kongsfjorden, Spitsbergen. Nor Polarinst Skr 172:33-60

Elverhoi A, Lonne O, Seland R (1983) Glaciomarine sedimentation in a modern fjord environment, Spitsbergen. Polar Res 1:127-149

Fauchald K, Jumars PA (1979) The diet of worms: a study of polychaete feeding guilds. Oceanogr Mar Biol Annu Rev 17:193-284

Ferraro SP, Cole FA (1990) Taxonomic level and sample size sufficient for assessing pollution impacts on the Southern California Bight macrobenthos. Mar Ecol Prog Ser 67: 251-262

Ferraro SP, Cole FA (1995) Taxonomic level sufficient for assessing pollution impacts on the southern California Bight macrobenthos-revisited. Environ Toxicol Chem 14:1031-1040

Gaston KJ (2000) Biodiversity: higher taxon richness. Prog Phys Geogr 24:117-127

Giangrande A, Licciano M, Musco L (2005) Polychaetes as environmental indicators-revisited. Mar Pollut Bull 50: 1153-1162

Hop H, Pearson TH, Hegseth EN, Kovacs KM and 24 others (2002) The marine ecosystem of Kongsfjorden, Svalbard. Polar Res 21:167-208

Kendall MA (1994) Polychaete assemblages along a depth gradient in a Spitsbergen Fjord. In: Dauvin JC, Laubier L, Reish DJ (eds) Actes de la 4eme Conference Internationale des Polychaetes. Mem Mus Natl Hist Nat 162: $463-470$

Lampadariou N, Karakassis I, Pearson TH (2005) Cost/benefit analysis of a benthic monitoring programme of organic benthic enrichment using different sampling and analysis methods. Mar Pollut Bull 50:1606-1618

Lefauconnier B, Hagen JO, Rudant JP (1994) Flow speed and calving rate of Kongsbreen glacier, Svalbard, using SPOT images. Polar Res 10: 59-65

Murina GV, Pancucci-Papadopoulou MA, Zenetos A (1999) The phylum Sipuncula in the eastern Mediterranean: composition, ecology, zoogeography. J Mar Biol Assoc UK 79:821-830

Olsgard F, Somerfield PJ (2000) Surrogates in marine benthic investigations - Which taxonomic unit to target? J Aquat Ecosyst Stress Recov 7:25-42

Olsgard F, Somerfield PJ, Carr MR (1997) Relationships between taxonomic resolution and data transformations in analyses of a macrobenthic community along an established pollution gradient. Mar Ecol Prog Ser 149:173-181

Olsgard F, Brattegard T, Holthe T (2003) Polychaetes as surrogates for marine biodiversity: lower taxonomic resolution and indicator groups. Biodiversity Conserv 12:1033-1049

Quijon PA, Snelgrove PVR (2005) Polychaete assemblages of a sub-arctic Newfoundland fjord: habitat, distribution, and identification. Polar Biol 28:495-505

Editorial responsibility: Howard Browman (Associate Editorin-Chief), Storebø, Norway
Roy K, Jablonski D, Valentine JW (1996) Higher taxa in biodiversity studies: patterns from eastern Pacific marine molluscs. Philos Trans R Soc Lond B 351:1605-1613

Smith SDA (2005) Rapid assessment of invertebrate biodiversity on rocky shores: where there's a whelk there's a way. Biodiver Conserv 14:3565-3576

Smith SDA, Simpson RD (1993) Effects of pollution on holdfast macrofauna of the kelp Ecklonia radiata: discrimination at different taxonomic levels. Mar Ecol Prog Ser 96:199-208

Somerfield PJ, Clarke KR (1995) Taxonomic levels, in marine community studies, revisited. Mar Ecol Prog Ser 127: 113-119

Svendsen H, Beszczynska-Moller A, Hagen JO, Lefauconnier $B$ and 11 others (2002) The physical environment of Kongsfjorden-Krossfjorden, an Arctic fjord system in Svalbard. Polar Res 21:133-166

Syvitski JPM, Burell CD, Skei JM (1987) Fjords: processes and products. Springer, New York

Thompson BW, Riddle MJ, Stark JS, Thompson BW (2003) Cost-efficient methods for marine pollution monitoring at Casey Station, East Antarctica: the choice of sieve meshsize and taxonomic resolution. Mar Pollut Bull 46: $232-243$

Urkiaga-Alberdi J, Pagola-Carte S, Saiz-Salinas JI (1999) Reducing effort in the use of benthic bioindicators. Acta Oecol 20:489-497

Vanderklift MA, Ward TJ, Jacoby CA (1996) Effect of reducing taxonomic resolution on ordinations to detect pollution-induced gradients in macrobenthic infaunal assemblages. Mar Ecol Prog Ser 136:137-145

Vanderklift MA, Ward TJ, Phillips JC (1998) Use of assemblages derived from different taxonomic levels to select areas for conserving marine biodiversity. Biol Conserv 86: 307-315

Warwick RM (1988a) Analyses of community attributes of the macrobenthos of Frierfjord/Langesundfjord at taxonomic levels higher than species. Mar Ecol Prog Ser 46:167-170

Warwick RM (1988b) The level of taxonomic discrimination required to detect pollution effects on marine benthic communities. Mar Pollut Bull 19:259-268

Warwick RM (1993) Environmental impact studies on marine communities: pragmatical considerations. Aust J Ecol 18: $63-80$

Włodarska-Kowalczuk M (2007) Molluscs in Kongsfjorden (Spitsbergen): species list and patterns of distribution and diversity. Polar Res 26:48-63

Włodarska-Kowalczuk M, Pearson TH (2004) Soft-bottom macrobenthic faunal associations and factors affecting species distributions in an Arctic glacial fjord (Kongsfjord, Spitsbergen). Polar Biol 27:155-167

Włodarska-Kowalczuk M, Weslawski JM, Kotwicki L (1998) Spitsbergen glacial bays macrobenthos - a comparative study. Polar Biol 20:66-73

Włodarska-Kowalczuk M, Pearson TH, Kendall MA (2005) Benthic response to chronic natural physical disturbance by glacial sedimentation in an Arctic fjord. Mar Ecol Prog Ser 303:31-41

Zajaczkowski M (2000) Doplyw i sedymentacja zawiesiny w wybranych fjordach zachodniego Spitsbergenu. PhD dissertation, Uniwersytet Gdanski, Gdynia

Submitted: February 23, 2007; Accepted: June 25, 2007

Proofs received from author(s): November 15, 2007 